\title{
Desenvolvimento Gerencial Integrado da Linha de Atenção às Urgências no Ambiente Intra-Hospitalar
}

Autores: Silva, G. M.; Carvalho, K. F.; Oliveira, A. C. Kato, M. Y.; Weber, B.

\section{INTRODUÇÃO}

A superlotação nos serviços de urgência é um fenômeno mundial sendo caracterizada pela ausência de leitos disponíveis, pacientes acamados nos corredores, tempo de espera para atendimento acima de uma hora, alta tensão na equipe assistencial e grande pressão para novos atendimentos. Nesse contexto o HCor em parceria com o Ministério da Saúde, no âmbito do Programa de Apoio ao Desenvolvimento Institucional do Sistema Único de Saúde (PROADI-SUS), vem desenvolvendo desde 2014 um projeto de intervenção que visa favorecer a introdução de mudanças no enfrentamento dos problemas relacionados ao fluxo dos pacientes agudos e agudizados nos serviços de urgência e emergência.

\section{OBJETIVO GERAL}

Apoiar e acompanhar a implementação de intervenções voltadas à gestão da assistência, contribuindo para qualificação da linha de atenção aos pacientes agudos e agudizados no ambiente intra-hospitalar no contexto da Rede de Atenção às Urgências.

\section{MÉTODO}

O projeto assume a educação permanente como eixo estruturante e com isso, a educação no/pelo trabalho é o elemento essencial da estratégia de mudança das atividades laborais nos serviços de saúde.

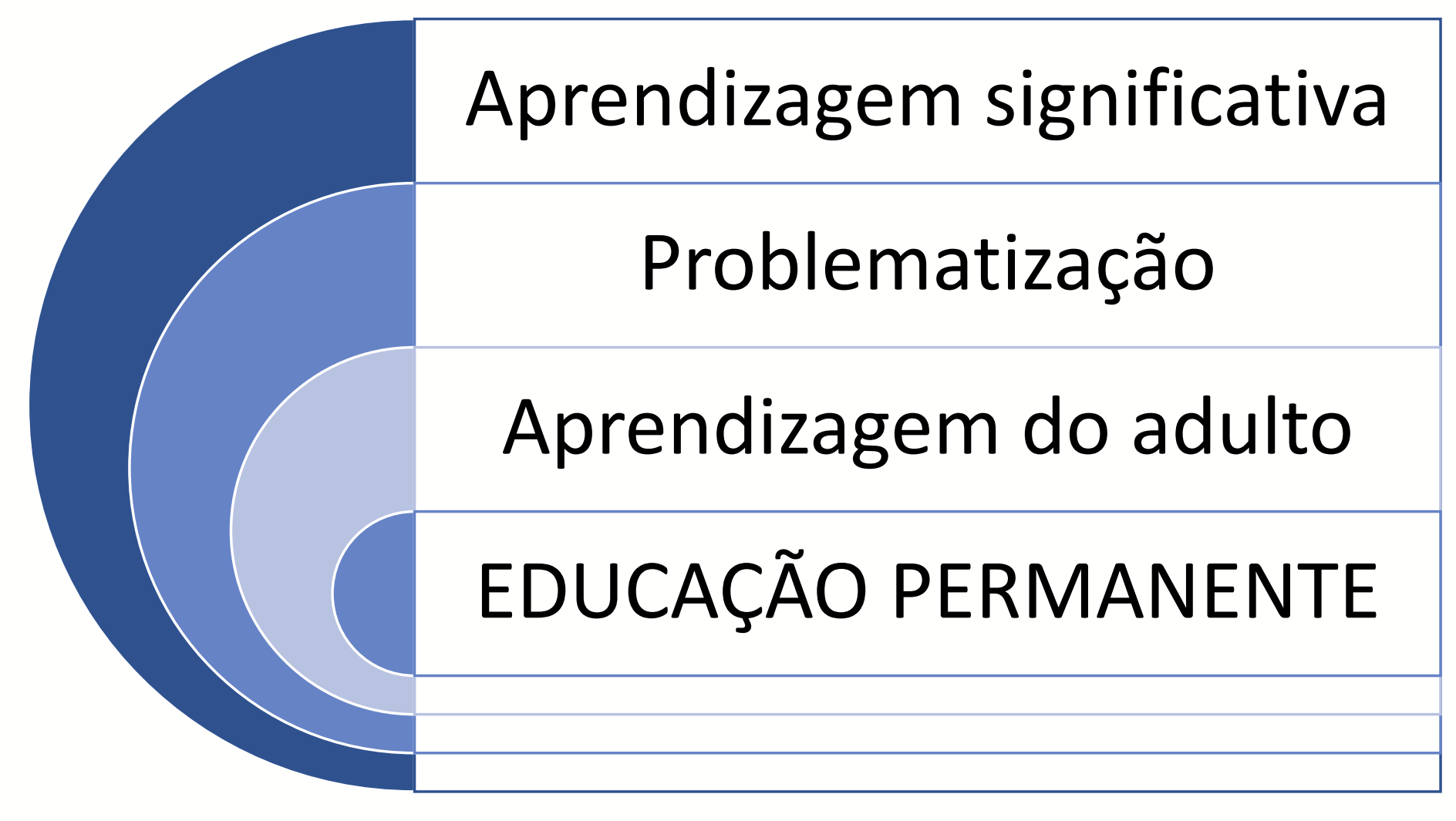

\section{Etapas:}

- Diagnóstico situacional dos hospitais

- Capacitação dos gestores dos hospitais

- Elaboração do Plano Aplicativo

- Elaboração da Planilha de indicadores

- Monitoramento dos indicadores

\section{RESULTADOS}

No período de 2014-2019 foram executadas 12 edições do Projeto nos estados (BA, CE, SP, AL, PA, PI, PE, MA, SE, GO e PB) com 1.230 profissionais capacitados de 142 instituições hospitalares, tendo como produto final um Projeto Gerencial por instituição.
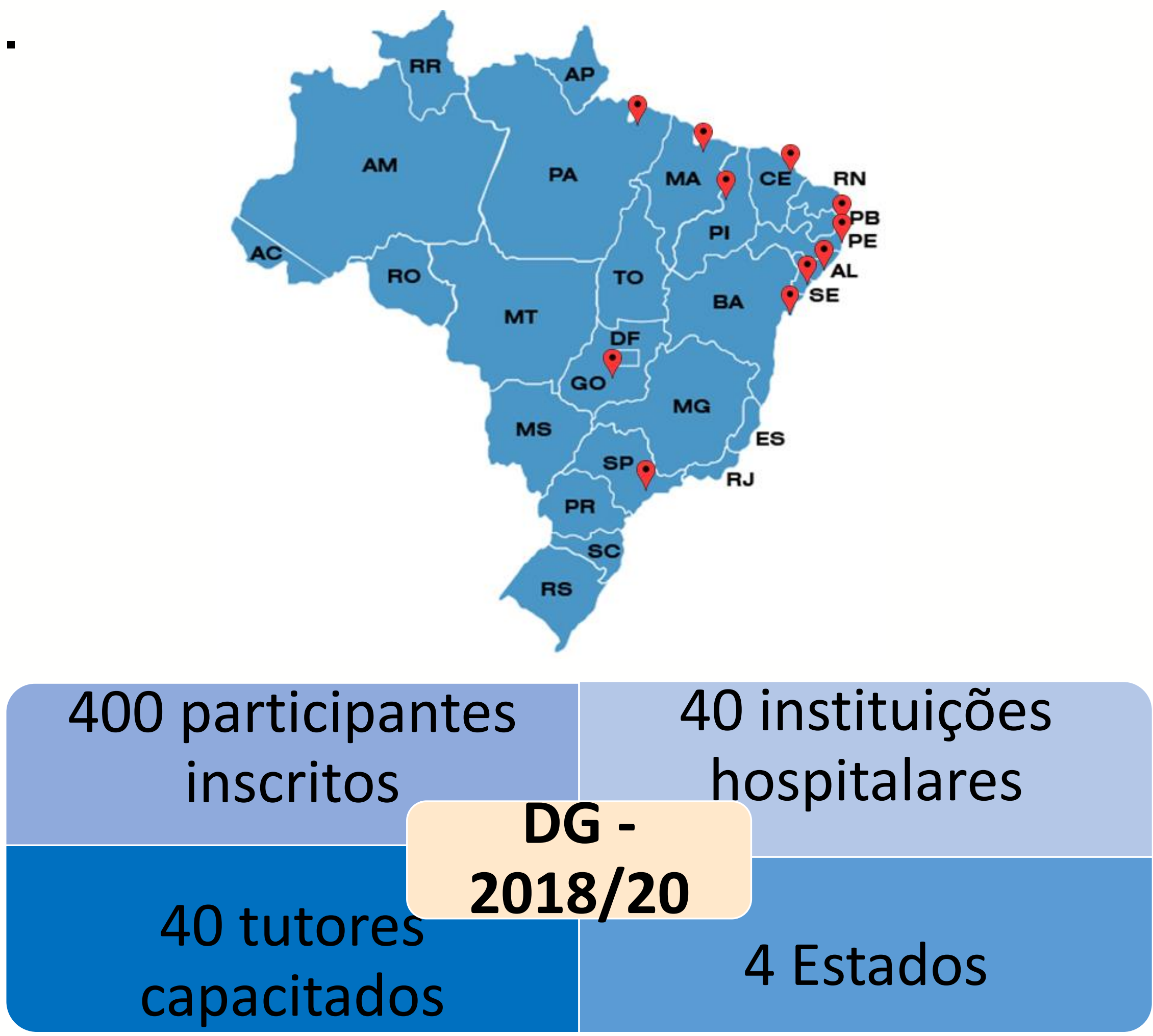

\section{CONSIDERAÇÕES}

A experiência de intervenção, na perspectiva da educação permanente, tem contribuído para a construção de um pensamento crítico, favorecendo que os participantes, utilizando diagnósticos situacionais, planejem ações que incidam no processo de trabalho e na estruturação do hospital.

\section{Referências}

BITTENCOURT, R.J., A superlotação dos serviços de emergência hospitalar como evidência de baixa efetividade organizacional, RJ: Escola Nacional de Saúde Pública Sergio Arouca; 2010.

BRASIL. MS. Secretaria de Atenção à Saúde. Departamento de Atenção Especializada. Manual instrutivo da Rede de Atenção às Urgências e Emergências no SUS. Brasília: Ed. do Ministério da Saúde, 2013. 